\title{
Research on Healthy China Guided School Sports Public Service under Global Governance
}

\author{
Feng $\mathrm{Li}^{1}, \mathrm{Lu} \mathrm{Liu}^{1}$ \\ ${ }^{1}$ Institute of Physical Education, Huanggang Normal University, Huangzhou 438000, Hubei, China \\ *Corresponding Author: Feng Li, Institute of Physical Education, Huanggang Normal University, \\ Huangzhou 438000, Hubei, China
}

\begin{abstract}
School sports in the state public service system should, carry out deepening reform comprehensively under the guidance of planning outline "Healthy China 2030", at a strategic level of global governance. We combine theoretical system of global governance elements with practical experience of sports public service, and apply literature consultation and logical deductive method into researching. With investigation on study trends in global governance and sports public service, we discussed realistic puzzlement and strategic choice in "Healthy China" leading school sports public service under global governance from value, rulemaking, subjective interest, objective function and integrated support.
\end{abstract}

Keywords: Sports health education, school sports, sports public service

\section{INTRODUCTION}

Global governance refers to a practice, in which nearly all fields in the world including public, private agencies and individuals establish and implement binding international regulation to solve global public problems and finally reach the goal of promoting global common interest. Basic characteristics of global governance are mainly as follows: first, global governance possesses mechanism that is available for implementing several decisions even though lacking of some kind of central authority in the world, that is to say, it essentially bases on the basis of global governance mechanism and weakens government authority; second, it has a complex construction with actors and sports at different levels, which focuses on pluralism and diversity of actors. In this case, it by no means excludes the important role of state government, but insists on that state government is just a part of actors in global governance. All non-state actors are equal to state government (Cao \& $\mathrm{Yu}, 2010)$; they should negotiate and cooperate to solve common issues at a level of region and even the world; third, the way of global governance is participation, negotiation and coordination, which stresses the equal importance of basic principle in procedure and essence, regards "project planning", "partnership", "consensus" as key words; fourth, there are close relations between global governance and global order, the later covers regularly arrangement in different developmental stage of politics, some are fundamental while others are programmed. Global governance can be regarded as the integration of global order and intentionality (Chen \& Ji, 2002).

In "Opinions on strengthening school sports and facilitating students" all-around development with both physically and mentally health from the General office of the State Council" issued in May.6th, 2016, strategic deployment as "strengthening physical education course and extracurricular exercises, and facilitating youth mental and physical health and fitness" has been made. The youth being both physically and mentally healthy, strong-willed and full of vigor is a manifestation of national vitality, a symbol of social civilization and progress and also a major part of the national comprehensive strength. Physical exercise is one of the effective ways to enhance students' quality of health, which plays an indispensable role in the formation of youth ideology

and morality, intelligence development, aesthetic accomplishment and healthy lifestyle. Strengthen school sports is an important way to the implementation of quality-oriented education and promotion to all-around development of students. This is very important for advancing modernization of education, construction of healthy China and strong human resources nation, and realization the Chinese dream of the great rejuvenation of the Chinese nation ( $\mathrm{Hu} \&$ Wang, 2014).

On Oct.25th, "Healthy China 2030" planning outline (hereinafter referred as outline) was issued by the Central Committee of the Communist Party of China. The outline is a program of action 
that boosts construction of healthy China in the future 15 years and also a major measure to ensure national health and even all-around well-being. Everyone should participate in and be healthy and take responsibility in the construction of healthy China (Ye, 2012).

\section{STATE OF THE LITERATURE}

- Global governance has shown a major tendency as strategic choice, positive participation, unique pattern, international regimes and transcending reality.

- Sports public service has been long researched, which mainly shows a tendency in development on the basis of equity and efficiency, organization system, human rights situation, health system and security mechanism.

- Realistic puzzlement in "Healthy China" guided school sports public service has remained, and regulation of school sports public service and integrated support system would become a hotspot in future study.

\section{CONTRIBUTION OF THIS PAPER TO THE LITERATURE}

- Exploration on school sports in public service system at a level of global governance based strategy guided by "Healthy China 2030" Plan has put forward a new horizon for the comprehensively deepening reform of school sports.

- The integration of global governance elements theoretical system and sports public service practical experience has further realized the scope of school sports public service.

- Exploration of realistic puzzlement and strategic choice in school sports public service guided by "Healthy China" under global governance respectively from values, rulemaking, subjective interest, objective function and integrated supports has provided theoretical references for the reform of China's school sports public service.

It is mentioned in the outline that the standardized rate of school sports grounds and facilities configuration would reach $100 \%$, young students would go in for moderate sports activities for over 3 times every week, and excellent rate of fitness and health standards of national students would be over $25 \%$ by 2030 (Li, 2011; Liu \& Li, 2016). As an important part of national public service system, school physical education would surely step into an important opportunity period of strategic development in the all-around deepening reform under the guidance of national building "Healthy China" in an around-way (Huang, 2011). "Healthy China" is a national health undertaking that belongs to our national level, however, the field of school sports should make a due contribution to realize national shared "Healthy China" through closely following advanced global governing theory and practices, as world is closely linked by informatization (Hu \&Chen, 2013).

\section{Study Trends in Global Governance And Sports Public Service}

\subsection{Study Trends in Global Governance}

Study on global governance field has mainly tended to be on the basis of strategic choice, positive participation, unique pattern, international system, transcending reality in recent five years. In the article "Tendency of global governance and Strategic choice of China", Keping Yu put forward his ideas of study that "global governance" referred to "a practice that solved global political, economic, ecological and security issues through binding international regimes and effective international cooperation so as to maintain normal order of international politics and economy (Zhen, 2007)." Study on China's strategic choices in global governance could start fromvalue, regimes, subject, object and results; In "Global governance: China's strategic measurements", Zhongying Pang and Ruiping Wang suggested that "the major difference in China engagement in global governance lies in its position and conditions of developing country by comparing to other countries (Zhou et al., 2012)." In "China and global governance-progress, behavior, structure and knowledge", Changhe Su suggested "Binary coordination in internal and external politics was unique pattern of China participating in global governance and even its foreign relations." In the article "Institutional dilemma and reform of present global governance", Jing Lu suggested that "Complex, intersectionality and correlation development in global issues should start from value, norm and actual effects of international system to enhance efficiency of 
system." In the article "Research Review on domestic "Global governance", Chengxin Chen suggested that "'Global governance' is nothing but a tool of thought that used, if it could not transcend limits of reality but fall under realistic conditions' influence (Li \& Liu, 2017)."

\subsection{Study Trends in Sports Public Service}

Sports public service has been long researched, which mainly shows a tendency in development on the basis of equity and efficiency, organization system, human rights situation, health system and security mechanism. In the article "Ideas and goals of public sports service development", Xuemei Pan and Bingyou Fan suggested that "starting point of sports public service is human centered, value basis is integrity and justice, ambition is solidarity and cohesion, development motivation is supply driven by demand, development point of equilibrium is public sharing between fairness and efficiency, base of realization is perfected development idea of sports public service system (Wang \& Wu, 2010)." In the article "Public Service Supply Mode Transformation and Realistic Choice Since 30 Years of Reform and Opening up in China", Yu Liu suggested the system framework of multiple competition and cooperation" and "establish system platform that government equally faces to sports non-profit organization" (Liu, 2013); In the article "On Public Service of Sports for the Protection of Health Rights_- In the Sight of Human Rights", Xiaolan Ye suggested that "Sports was an important way to facilitate health of national people, and sports public service was very important for upgrading the human rights situation of a country." In the article "Establishment of University sports public service system platform", Yingchuan Chen and Jianqiu Ji suggested that "As base of sources of intelligence and information, university should provide high quality health capital to society" "they should promote efficiency of human power capital investment and form into network system of lifelong fitness"; In the article "Study on university sports public service", Qin Wang and Ying Wu presented ideas of "Multi-channel raised Fund guarantee system", "mechanism of supervision, motivation and assessment" and "timely introduction of market mechanism" (Pan \& Fan, 2010; Yang, 2013).

\section{Realistic Puzzlement in "Healthy China" Guided School Sports Public Service UNDER GLOBAL GOVERNANCE}

In the value of health, globalization of western health value affected localization development of China's school sports, resulting in deficiency in the inheritance of unique health value system formed by traditional culture with Chinese characteristics through school sports. In the article "Establishment of traditional ethnic sports public service system in the process of urbanization", Jianxun Liang, Hua Wang and Guanghui Zhou thought that "Traditional ethnic sports culture should be important contents in sports public service at all government sectors, and meanwhile reinforced as the important mean of sports public function at all government sectors."

In the rulemaking of health, declination of China's right of speech in the process of rulemaking regarding school sports of global health undertakings, has led to the inclination of governing Chinese school sports "Healthy China" aimlessly following health governance mode of developed countries. In the article "Study on implementation of sports public service standardization in China", Ming Yang put forward the idea "Establishment of sports public service standardized system should define the orientation of stages, and advance them by layers; efforts should have made to study on sports public service standardization and propagandize training and guiding of policies and regulations and other main conceives and countermeasures in the implementation of sports public service standardization."

In the subjective interest of health, western countries have attached equal importance to multisubject interest sharing in sports public service, while school sports "Healthy China" in China has by far employed the way of promotion in the policy of government-led. In the article "Study on the Path Choice of NPOs of Sports' Participation in Sports Public Service", Zi Lin thought that "To solve short supply and imbalance development in current sports public service, efforts should be made to promote the engagement of public and social organization and form into mechanism of multi-cooperation (Lin, 2012)."

In the objective function of health, China's school sports have just started reform and development guided by public policies of "Healthy China", and it is difficult to acquire such a 
clear and stable scope of objective functions as America and European countries. In the article "The United States and Britain and Japan City Community Sport Public Service Construction Experience and Its Enlightenment to China”, Tao Zhou, Fenghua Zhang, Zhennan Su suggested to "Bring functions and roles of government, society, school, community sports fitness clubs and community residents' in jointly participation in city and community sports public service construction into full play".

In the integrated support of health, America, Britain and Japan has attached great importance to sports public service and well-equipped city sports facilities and playgrounds including schools. China, however, has remained regional disparity and imbalance in configuration of school sports. In the article "On the Realization of Sport Public Service Equalization: Functions and Measures of Public Fiscal System", Wei Hu and Yaping Cheng put forward that "Equalization in sports public service should be implemented to solve the contradiction in the disparity among cities and villages, regions and groups".

\section{Strategic Choices in "Healthy China" Guided School Sports Public Service UNDER GLOBAL GOVERNANCE}

Reinforce inheritance of China unique health value system by school sports and dynamic integrate with beneficial achievement of western mainstream value of health. In the article "Value Consideration and Predicament of Sport Public Service Supply in Rural Areas", Qingshan $\mathrm{Hu}$ and Jian Wang put forward the idea of "returning to original source of public service, considering and questioning value orientation of rural sports public service supply from logical starting point", "Orientation of people's demand in rural sports public service supply was a kind of value appeal that decides rural sports public service supply by peasants' sports demand."

Upgrade China's right of speech regarding school sports in the rulemaking process of global health undertaking so as to form into governance mode of China's school sports "Healthy China". In the article "On the Integration of Transformation in Sports Differentiation and the Sports Public Service System of the Government", Haojun Huang suggested that "actual distribution of service sources should be considered, laws and regulations should be relied to support and reposition right and obligation of all roles of participants."

Speed up the transformation of promotion way of unitary government "Health China" policies; realize Chinese school sports public service multi-subject interest sharing as soon as possible. In the article "On the diversification of sports public service supplying subjects", Keqiang Cao, Lin $\mathrm{Yu}$ suggested that "Mechanism should be made to negotiate and coordinate government itself and social non-profit organization and market commercial organizations to achieve multiple supply of sports public service and maximize colorful sports public service for citizens."

Consolidate a clear and stable scope of school sports objective functions guided by "Healthy China", steadily work through restriction of inherent shortages in development conditions. In the article "The Government Public Service Function Orientation and Optimization Strategy", Jingping Li thought that "“"Government macro-control function should be embodied in reinforcing control capacity of overall situation rather than controlling various sports public service production and relative specific business activities. Thus, government should put more effort and money into organizing fundamental sports public service and sports public products supply."

Promote modernization of integrated support of China's school sports facilities and playgrounds; strive to implement equalized regional progress in school sports public service. In the article "Equalization policies and enlightenment on Developed countries' sports public service", Yu Liu supposed that "The only way out for China's sports public service equalization policies was to fully draw on foreign countries' experiences, carry out localization transformation, seek suitable theories and methods for local experiences."

\section{CONCLUSION}

In the era of global governance, any country, organization or individual may is inevitably affected and exerts impacts on it. No matter implementation of public policies of "Healthy 
China", or deepening reform of school sports public service comprehensively, could not explore realistic puzzlement and strategic choices in the reform and development without the research system that comprises of global governance value, rules, subject, object and results. Thus, mutual promotion and influence surely occur to governance in the world.

\section{REFERENCES}

[1] Cao, K.Q., \& Yu, L. (2010). On the diversification of sports public service supplying subjects. Jounal of Physical Education, 17(10), 22-25. DOI: 10.3969/j.issn.1006-7116.2010.10.005.

[2] Chen, Y.C., \& Ji, J.Q. (2002). The Constructing Research on Communality Service System Platform of Physical Education in College. China Sport Science and Technology, 38(11), 49-51. DOI: 10.3969/j.issn.1002-9826.2002.11.017.

[3] Huang, H.J. (2011). On the Integration of Transformation in Sports Differentiation and the Sports Public Service System of the Government. Journal Of Shanghai Physical Education Institute, 35(6), 28-31.DOI : 10.3969/j.issn.1000-5498.2011.06.007.

[4] Hu, W., \&Chen, Y.P. (2013). On the Realization of Sport Public Service Equalization: Functions and Measures of Public Fiscal System. Journal of Shanghai University of Sport, 37(3), 37-45. DOI: 10.3969/j.issn.1000-5498.2013.03.007.

[5] Hu, X.S., \&Wang, J. (2014). Value Consideration and Predicament of Sport Public Service Supply in Rural Areas. Journal of Shanghai University of Sport, 38(4), 20-24,30. DOI: 10.3969/j.issn.10005498.2014.04.004.

[6] Li, F., \& Liu, L. (2017). The Experience and Enlightenment of Developed-country Governments Purchase Public Sports Service. The Journal of Yunnan Administration College, (2), 157-164. DOI: 10.16273/j.cnki.53-1134/d.2017.02.026.

[7] Li, J.P. (2011). The Government Public Service Function Orientation and Optimization Strategy. Sports \& Science, 32(3), 69-72. DOI: 10.3969/j.issn.1004-4590.2011.03.012.

[8] Lin, Z. (2012). Study on the Path Choice of NPOs of Sports' Participation in Sports Public Service. Sports \& Science, 33(3), 110-112,117. DOI: 10.3969/j.issn.1004-4590.2012.03.024.

[9] Liu, L., \&Li, F. (2016). Confusion and Direction of School Sports Facilities Open to Public. Journal of Shenyang Sport University, 35(3), 30-35. DOI: 10.3969/j.issn.1004-0560.2016.03.006.

[10] Liu, Y. (2013). Public Service Supply Mode Transformation and Realistic Choice Since 30 Years of Reform and Opening up in China. China Sport Science, 33(2), 11-21. DOI: 10.3969/j.issn.1000677X.2013.02.002.

[11] Pan, X.M., \& Fan, B.Y. (2010). Ideas and Goals of Public Sports Service Development. Journal of Shanghai University of Sport, 34(3),10-14. DOI: 10.3969/j.issn.1000-5498.2010.03.003.

[12] Wang, Q., \& Wu, Y. (2010). Research on Public Sports Service in Higher Learning Institutions. Journal of Shanghai University of Sport, 34(3), 19-22, 37. DOI: 10.3969/j.issn.10005498.2010.03.005.

[13] Yang, M. (2013). A study of implementing sports public service standardization in China. Journal of Physical Education, 20(06), 38-43. DOI: 10.3969/j.issn.1006-7116.2013.06.009.

[14] Ye, X.L. (2012). On Public Service of Sports for the Protection of Health Rights_— - In the Sight of Human Rights. Sports \& Science, 33(3), 26-29, 60. DOI: 10.3969/j.issn.1004-4590.2012.03.006.

[15] Zhen, B.Y. (2007). Retrospection and Prospect on Studies of Global Governance. Teaching and Research, (4), 76-83. DOI: 10.3969/j.issn.0257-2826.2007.04.012.

[16] Zhou, T., Zhang, F.H., \& Su, Z.N. (2012). The United States and Britain and Japan City Community Sport Public Service Construction Experience and Its Enlightenment to China. Sports \& Science, 33(4), 69-74. DOI: 10.3969/j.issn.1004-4590.2012.04.017.

Citation: Feng, Li, and Liu Lu. "Research on Healthy China Guided School Sports Public Service Under Global Governance." International Journal of Sports and Physical Education (IJSPE), vol 3, no. 4, 2017, pp. 7-11. doi:http://dx.doi.org/10.20431/2454-6380.0304002.

Copyright: () 2017 Authors. This is an open-access article distributed under the terms of the Creative Commons Attribution License, which permits unrestricted use, distribution, and reproduction in any medium, provided the original author and source are credited. 